\title{
Investigating the Presence of Interattack Astrocyte Damage in Neuromyelitis Optica Spectrum Disorder
}

\author{
Longitudinal Analysis of Serum Glial Fibrillary Acidic Protein
}

Jae-Won Hyun, MD, PhD, Yeseul Kim, MSc, So Yeon Kim, BS, Min Young Lee, MD, Su-Hyun Kim, MD, PhD, and Ho Jin Kim, MD, PhD

Neurol Neuroimmunol Neuroinflamm 2021;8:e965. doi:10.1212/NXI.0000000000000965

\section{Abstract}

\section{Objectives}

Information on subclinical astrocyte damage can provide further insight into neuromyelitis optica spectrum disorder (NMOSD) pathophysiology and disease-monitoring strategies. To investigate whether astrocyte and neuroaxonal damage occurs during interattack periods in individuals with NMOSD through longitudinal measurement of serum glial fibrillary acidic protein (sGFAP) and neurofilament light chain ( $\mathrm{sNfL}$ ) at multiple time points.

\section{Methods}

sGFAP and sNfL levels were measured in 187 serum samples from 20 participants with NMOSD treated with rituximab (median follow-up: 24 months) and 19 age-/sex-matched healthy controls using a highly sensitive single-molecule array assay. From the NMOSD cohort of National Cancer Center, Korea, 14 clinically stable participants were randomly selected for focused investigation of interattack periods, and 6 participants with clinical attacks despite treatment were enrolled for attack-related measurements.

\section{Results}

Significant elevations of sGFAP levels were observed in all clinical attacks, and 95\% (19/20) of patients showed reduction of sGFAP levels below the cutoff value (3 SDs above mean levels in age-/sex-matched healthy controls) within 3 months of their clinical attacks. The sGFAP levels were consistently low during interattack periods in $90 \%(17 / 19)$ of patients whose sGFAP levels returned to below the cutoff value. Changes in sNfL levels were similar to but slower than those in sGFAP levels.

\section{Conclusions}

Subclinical astrocyte damage represented by increasing sGFAP levels rarely occurred during interattack periods in individuals with NMOSD; however, a certain degree of astrocyte damage did occur at the time of clinical attacks without exception, but it was not evident within 3 months of the attack.

\section{Correspondence \\ Dr. Kim}

hojinkim@ncc.re.kr

\section{RELATED ARTICLE}

\section{Editorial}

The Calm Between Storms: Serum Biomarkers in Assessing Interattack Astrocytopathy in Neuromyelitis Optica Spectrum Disorder

Page e988 


\section{Glossary}

AQP4 = aquaporin-4; EDSS = Expanded Disability Status Scale; NCC $=$ National Cancer Center; NMOSD = neuromyelitis optica spectrum disorder; sGFAP = serum glial fibrillary acidic protein; sNfL = serum neurofilament light chain.

Neuromyelitis optica spectrum disorder (NMOSD) is a primary astrocytopathy mediated by antibodies against aquaporin-4 (AQP4), a water channel protein mainly expressed in astrocytes. ${ }^{1}$ Glial fibrillary acidic protein (GFAP) is a component of the astrocyte cytoskeleton, and its presence in bodily fluids is believed to reflect the extent of astrocyte damage. ${ }^{2}$ Having been shown the good correlation of GFAP levels between CSF and serum, serum GFAP (sGFAP) is considered as a potential biomarker for disease activity in individuals with NMOSD. ${ }^{3}$

Clinical events in individuals with NMOSD can result in significant astrocyte damage ${ }^{2,3}$; however, it is unclear whether astrocyte damage can occur in the absence of a clinical attack. Defining subclinical astrocyte damage may provide insights into NMOSD pathophysiology and lead to establishment of disease-monitoring strategies. This study addressed whether astrocyte damage can occur during interattack periods by longitudinally measuring sGFAP levels at multiple time points.

\section{Methods}

A total of 187 sera were analyzed; 168 samples from 20 individuals with NMOSD and 19 samples from 19 age- and sexmatched healthy volunteers. All individuals satisfied the 2015 diagnostic criteria for NMOSD and were positive for AQP4 antibodies tested by live cell-based assays. ${ }^{4,5}$ Twenty participants newly treated with rituximab according to Kim protocol $^{6}$ and underwent at least a 24-month follow-up were randomly selected from the NMOSD cohort of the National Cancer Center (NCC) to minimize interindividual variability of treatment; 14 participants without clinical attacks (stable) during follow-up were included for focused investigation of interattack periods, and 6 participants with clinical attacks (unstable) were included for attack-related measurements. Clinical attacks were defined as previously described, ${ }^{6}$ and other clinical information including Expanded Disability Status Scale (EDSS) scores was collected by retrospective review of medical records.

To investigate the change of sGFAP and serum neurofilament light chain (sNfL) levels at the time of attacks and after attacks, serum samples were collected within 1 month of the attacks and at 1-month intervals for 3 months following the attacks. To investigate the presence of subclinical astrocyte and neuroaxonal damage during interattack periods, serum samples were collected every 3 months during the first year and every 6 months during the second year of follow-up. Pretreatment samples were collected within a median of 2 months (range 1-3 months) from prior attacks. The median number of samples per participants was 8 , and the median follow-up period after initiation of rituximab therapy was 24 months (range 24-26 months).

sGFAP and sNfL concentrations were measured using a single-molecule array assay (Simoa, Quanterix, MA). sGFAP and sNfL levels were independently evaluated by a blinded examiner in duplicate, and mean intra-assay and interassay coefficients of variation were below $10 \%$. Cutoff values for the sGFAP $(221.7 \mathrm{pg} / \mathrm{mL})$ and sNfL $(16.8 \mathrm{pg} / \mathrm{mL})$ of participants with NMOSD were calculated as 3 SDs higher than mean values of their age- and sex-matched healthy controls.

\section{Statistical Analysis}

A Fisher exact test was applied to determine the statistical significance of the cutoff value-based positive or negative statuses of sGFAP and sNfL levels, measured at individual time points, were associated with clinical relapse or relapsefree status.

\section{Standard Protocol Approvals, Registrations, and Patient Consents}

The Institutional Review Board of the NCC approved the study, and written informed consent was obtained from all participants.

\section{Data Availability}

Anonymized data not published within this article will be made available on request from any appropriately qualified investigator.

\section{Results}

The median age at sampling and female-to-male ratio of participants with NMOSD and healthy controls were 34 and 33 years and 9:1 and 8.5:1, respectively (table 1 ). All participants were Korean. The median disease duration at baseline was 3 years, and the median follow-up duration was 24 months. The median EDSS scores at baseline and at the last visit were 4.0 and 3.5 , respectively.

Figure 1 shows overall trends of longitudinal changes of sGFAP and sNfL. Elevated sGFAP levels were observed at all clinical attacks (figure e-1, links.lww.com/NXI/A441, A-C, $\mathrm{N}, \mathrm{O}-\mathrm{T})$. However, within 3 months of their clinical attacks, sGFAP levels returned to below cutoff value in 95\% (19/20) of the participants (figure e-1A-S). One exception (figure e-1T) maintained marginally higher sGFAP levels following a clinical relapse. Sustained low sGFAP levels during 
A

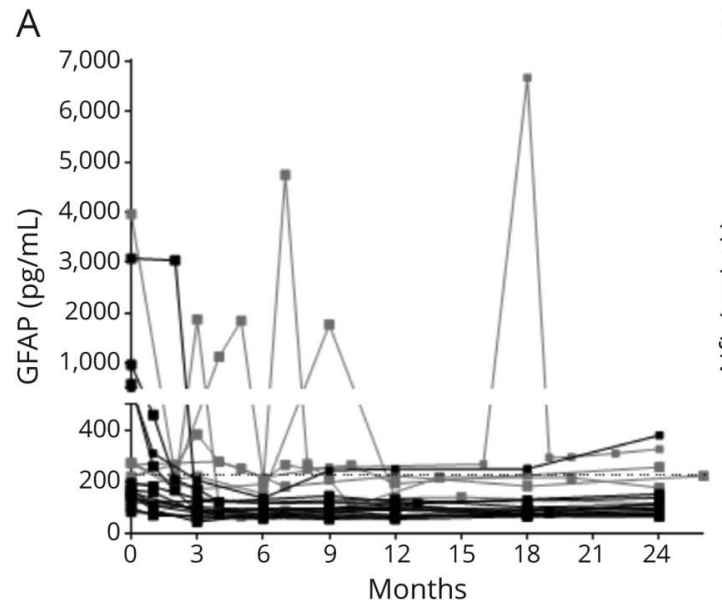

B

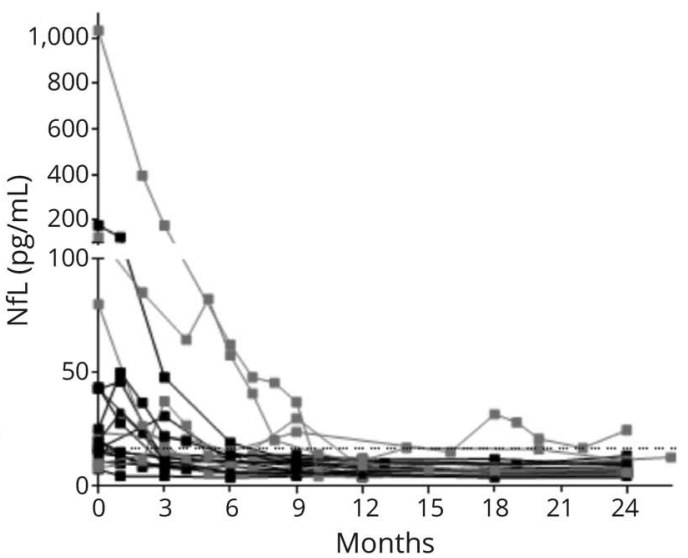

Black = stable group; gray = unstable group; sGFAP = serum glial fibrillary acidic protein; sNfL = serum neurofilament light chain .

interattack periods were observed in $90 \%$ (17/19) of participants with stabilized sGFAP levels after attacks (figure e-1A-M, O-R). Two participants (figure e-1N, S) showed slightly increased sGFAP levels in the absence of overt attacks.

sNfL levels also increased in all participants at the time of clinical attacks (figure e-1A-C, N, O-T, links.lww.com/NXI/ A441) and stabilized after the attacks, but at a rate slower than that of sGFAP levels (figure e-1B, C, O, P, S). Five participants showed higher sNfL levels but lower sGFAP levels than the respective cutoff values in the early phase of rituximab therapy (figure e-1D, F, H, J, L). Consistently low sNfL levels were observed during interattack periods in all participants except one, who showed marginally re-elevated sNfL levels without an overt attack (figure e-1T).

Supplemental table e-1, links.lww.com/NXI/A442, shows positive or negative status of sGFAP and sNfL using cutoff value at the individual time points according to the clinical relapse or clinical relapse-free status. There were statistical significances in both sGFAP and sNfL, respectively $(p<$ $0.001)$.

\section{Discussion}

Significantly increased sGFAP levels were observed at all clinical attacks, and none of the participants experienced clinical relapse when their sGFAP levels were below the cutoff value. All except 1 participant with NMOSD returned to normal sGFAP levels within 3 months of clinical attacks. During interattack periods, low sGFAP levels were stably maintained in $90 \%$ of participants with stabilized sGFAP levels after attacks. These results suggest that although astrocyte damage occurs at the time of clinical attacks without exception, it mostly ceases within 3

Table 1 Demographics

\begin{tabular}{lll}
\hline & NMOSD $(\mathbf{n = 2 0 )}$ & Controls $(\mathbf{n}=\mathbf{1 9})$ \\
\hline Female to male ratio & $9: 1$ & $8.5: 1$ \\
\hline Median age at sampling at baseline (y, IQR) & All Korean & All Korean \\
\hline Median disease duration at baseline (y, IQR) & $34(30 ; 38)$ & N/A \\
\hline Median follow-up duration (mo, IQR) & $3(1 ; 10)$ & N/A \\
\hline Median evaluated time points of sGFAP (IQR) & $24(24 ; 24)$ & N/A \\
\hline Median EDSS score at baseline (IQR) & $8(7 ; 9)$ & N/A \\
\hline Median EDSS score at the last visit (IQR) & $4.0(2.5 ; 4.5)$ & N/A \\
\hline
\end{tabular}

Abbreviations: EDSS = Expanded Disability Status Scale; IQR = interquartile range; N/A = not applicable; NMOSD = neuromyelitis optica spectrum disorder; sGFAP = serum glial fibrillary acidic protein. 
months and rarely occurs during interattack periods on proper treatment.

Several studies using radiologic or electrophysiologic parameters have suggested the possibility of occult injuries in individuals with NMOSD. ${ }^{7,8}$ sGFAP level can be evaluated as a biomarker of astrocyte damage, closely related with primary NMOSD pathology. However, only 1 cross-sectional observational study has linked sGFAP with subclinical astrocyte damage in some individuals with NMOSD treated with steroid and/or conventional immunosuppressant. ${ }^{3}$ Based on our longitudinal assessment of sGFAP levels, we show that subclinical astrocyte damage, represented by elevated sGFAP levels during interattack periods, is unusual in individuals with NMOSD treated with rituximab. Current longitudinal analysis of samples from multiple time points (median 8 per participants) could exclude interindividual variability and enable focused investigation of postattack and interattack periods.

One exceptional stable participant (figure e-1N, links.lww. com/NXI/A441) showed slightly high sGFAP levels without an overt clinical attack. It is possible that sensory paresthesia presented at the time of high sGFAP levels might not be accounted as a neurologic deterioration because of underlying sensory sequelae caused by prior repetitive myelitis. Two unstable participants (figure e-1S, T) showed re- or sustained elevation of sGFAP levels marginally higher than the cutoff value. This finding suggests that subclinical astrocyte damage may occur, although very rarely in individuals with NMOSD on proper treatment. However, there remains a concern regarding whether the optimal cutff value should be determined from healthy populations or intraindividually. In addition, whether there are any differences in protein (sGFAP) diffusion through blood-brain barrier in these individuals remains to be elucidated. ${ }^{9}$

Although this study focused on sGFAP because of its relationship with NMOSD pathology, longitudinal changes in sNfL levels were also evaluated. Changes in sNfL levels were similar to but slower than those in sGFAP levels. sNfL levels reflect neuroaxonal injury and imply inflammatory and/or neurodegenerative changes in $\mathrm{CNS}^{10}$ In contrast to subclinical neuroaxonal damage in individuals with $\mathrm{MS}$, ${ }^{\text {e1 }}$ elevated sNfL during interattack periods was uncommonly observed in individuals with NMOSD. These results support a hypothesis that NMOSD pathogenesis primarily entails attack-related neuroinflammation, probably without interattack neurodegenerative processes.

This study has some limitations. The number $(n=20)$ of participants with NMOSD was relatively small. Nevertheless, useful individualized information was obtained from 168 serum samples with over a 2-year follow-up. Second, other radiologic and/or electrophysiologic modalities to detect disease activity during interattack periods beyond clinical status were not included. Larger-scale prospective studies investigating various parameters of disease activity are warranted.

In conclusion, interattack astrocyte damage was rarely observed in individuals with NMOSD on appropriate treatment, whereas significant astrocyte damage was noted at the time of clinical attacks. These findings may provide further insight into the pathogenic mechanism of NMOSD and could be useful in the development of personalized disease-monitoring strategies.

\section{Study Funding}

This study was supported by the National Research Foundation of Korea (NRF-2020R1F1A1072174 and NRF2018R1A5A2023127).

\section{Disclosure}

Y. Kim, S.Y. Kim, and M.Y. Lee report no financial disclosures. J.-W. Hyun has received a grant from the National Research Foundation of Korea. S.-H. Kim has lectured, consulted, and received honoraria from Bayer Schering Pharma, Biogen, Genzyme, Merck Serono, and UCB and received a grant from the National Research Foundation of Korea. H.J. Kim has lectured, consulted, and received honoraria from Alexion, Celltrion, Eisai, HanAll BioPharma, Merck Serono, Novartis, Sanofi Genzyme, Teva-Handok, and Viela Bio; received a grant from the National Research Foundation of Korea; accepted research funding from AprilBio; serves on a steering committee for MedImmune/Viela Bio; and is a coeditor of the Multiple Sclerosis Journal and an associated editor of the Journal of Clinical Neurology. Go to Neurology.org/NN for full disclosures.

\section{Publication History}

Received by Neurology: Neuroimmunology \& Neuroinflammation August 10, 2020. Accepted in final form January 11, 2021.

Appendix Authors

\begin{tabular}{lll}
\hline Name & Location & Contribution \\
\hline $\begin{array}{l}\text { Jae-Won } \\
\text { Myun, } \\
\text { MD, PhD }\end{array}$ & $\begin{array}{l}\text { Research Institute and } \\
\text { Cospital of National Cancer } \\
\text { Center, Goyang, Korea }\end{array}$ & $\begin{array}{l}\text { Designed and } \\
\text { conceptualized the study; } \\
\text { analyzed the data; and } \\
\text { drafted and revised the } \\
\text { manuscript for intellectual } \\
\text { content }\end{array}$ \\
\hline $\begin{array}{l}\text { Yeseul } \\
\text { Kim, MSc }\end{array}$ & $\begin{array}{l}\text { Research Institute and } \\
\text { Cospital of National Cancer }\end{array}$ & $\begin{array}{l}\text { Major role in the acquisition } \\
\text { of data }\end{array}$ \\
\hline $\begin{array}{l}\text { So Yeon } \\
\text { Kim, BS }\end{array}$ & $\begin{array}{l}\text { Research Institute and } \\
\text { Hospital of National Cancer } \\
\text { Center, Goyang, Korea }\end{array}$ & $\begin{array}{l}\text { Major role in the acquisition } \\
\text { of data }\end{array}$ \\
\hline $\begin{array}{l}\text { Min } \\
\text { Young } \\
\text { Lee, MD }\end{array}$ & $\begin{array}{l}\text { Research Institute and } \\
\text { Hospital of National Cancer } \\
\text { Center, Goyang, Korea }\end{array}$ & $\begin{array}{l}\text { Major role in the acquisition } \\
\text { of data }\end{array}$ \\
\hline
\end{tabular}




\section{Appendix (continued)}

\begin{tabular}{lll}
\hline Name & Location & Contribution \\
\hline $\begin{array}{l}\text { Su-Hyun } \\
\text { Kim, MD, } \\
\text { PhD }\end{array}$ & $\begin{array}{l}\text { Research Institute and } \\
\text { Hospital of National Cancer } \\
\text { Center, Goyang, Korea }\end{array}$ & $\begin{array}{l}\text { Major role in the acquisition } \\
\text { of data and revised the } \\
\text { manuscript for intellectual } \\
\text { content }\end{array}$ \\
\hline $\begin{array}{l}\text { Ho Jin } \\
\text { Kim, MD, } \\
\text { PhD }\end{array}$ & $\begin{array}{ll}\text { Research Institute and } \\
\text { Cospital of National Cancer }\end{array}$ & $\begin{array}{l}\text { Designed and } \\
\text { conceptualized the study; } \\
\text { analyzed the data; and } \\
\text { revised the manuscript for } \\
\text { intellectual content }\end{array}$ \\
\hline
\end{tabular}

\section{References}

1. Lennon VA, Kryzer TJ, Pittock SJ, Verkman AS, Hinson SR. IgG marker of opticspinal multiple sclerosis binds to the aquaporin-4 water channel. J Exp Med 2005;202: 473-477.

2. Misu T, Takano R, Fujihara K, Takahashi T, Sato S, Itoyama Y. Marked increase in cerebrospinal fluid glial fibrillar acidic protein in neuromyelitis optica: an astrocytic damage marker. J Neurol Neurosurg Psychiatry 2009;80:575-577.
3. Watanabe M, Nakamura Y, Michalak Z, et al. Serum GFAP and neurofilament light as biomarkers of disease activity and disability in NMOSD. Neurology 2019;93:e1-e13.

4. Wingerchuk DM, Banwell B, Bennett JL, et al. International consensus diagnostic criteria for neuromyelitis optica spectrum disorders. Neurology 2015; 85:177-189.

5. Kim Y, Kim G, Kong BS, et al. Large-scale in-house cell-based assay for evaluating the serostatus in patients with neuromyelitis optica spectrum disorder based on new diagnostic criteria. J Clin Neurol 2017;13:175-180.

6. Kim SH, Jeong IH, Hyun JW, et al. Treatment outcomes with rituximab in 100 patients with neuromyelitis optica: influence of FCGR3A polymorphisms on the therapeutic response to rituximab. JAMA Neurol 2015;72:989-995.

7. Ringelstein $\mathrm{M}, \mathrm{Harmel} \mathrm{J}$, Zimmermann $\mathrm{H}$, et al. Longitudinal optic neuritis-unrelated visual evoked potential changes in NMO spectrum disorder. Neurology 2020;94:1-12.

8. Ventura RE, Kister I, Chung S, Babb JS, Shepherd TM. Cervical spinal cord atrophy in NMOSD without a history of myelitis or MRI-visible lesions. Neurol Neuroimmunol Neuroinflamm 2016;3:e224.

9. Piehl F, Kockum I, Khademi M, et al. Plasma neurofilament light chain levels in patients with MS switching from injectable therapies to fingolimod. Mult Scler 2018; 24:1046-1054.

10. Hyun JW, Kim Y, Kim G, Kim SH, Kim HJ. Longitudinal analysis of serum neurofilament light chain: a potential therapeutic monitoring biomarker for multiple sclerosis. Mult Scler 2020;26:659-667.

(Additional e-reference 1 available at: links.lww.com/NXI/A442.) 


\section{Neurology \\ Neuroimmunology \& Neuroinflammation}

\section{Investigating the Presence of Interattack Astrocyte Damage in Neuromyelitis Optica Spectrum Disorder: Longitudinal Analysis of Serum Glial Fibrillary Acidic Protein Jae-Won Hyun, Yeseul Kim, So Yeon Kim, et al. \\ Neurol Neuroimmunol Neuroinflamm 2021;8; \\ DOI 10.1212/NXI.0000000000000965}

This information is current as of April 9, 2021

Updated Information \& Services

References

Citations

Subspecialty Collections

Permissions \& Licensing

Reprints including high resolution figures, can be found at: http://nn.neurology.org/content/8/3/e965.full.html

This article cites 10 articles, 3 of which you can access for free at: http://nn.neurology.org/content/8/3/e965.full.html\#\#ref-list-1

This article has been cited by 1 HighWire-hosted articles: http://nn.neurology.org/content/8/3/e965.full.html\#\#otherarticles

This article, along with others on similar topics, appears in the following collection(s):

Devic's syndrome

http://nn.neurology.org//cgi/collection/devics_syndrome

Information about reproducing this article in parts (figures,tables) or in its entirety can be found online at:

http://nn.neurology.org/misc/about.xhtml\#permissions

Information about ordering reprints can be found online: http://nn.neurology.org/misc/addir.xhtml\#reprintsus

Neurol Neuroimmunol Neuroinflamm is an official journal of the American Academy of Neurology.

Published since April 2014, it is an open-access, online-only, continuous publication journal. Copyright

Copyright (C) 2021 The Author(s). Published by Wolters Kluwer Health, Inc. on behalf of the American

Academy of Neurology.. All rights reserved. Online ISSN: 2332-7812.

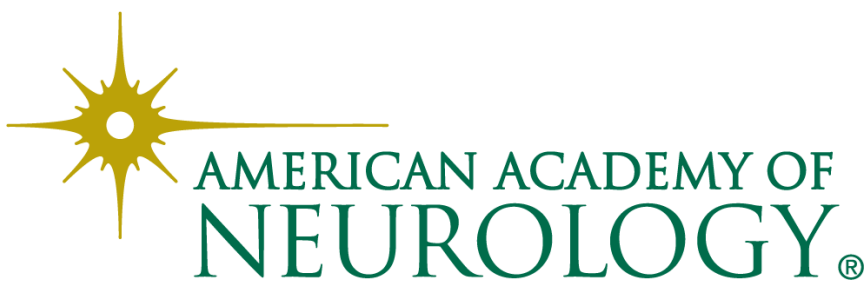

